\title{
Research on the Applications of Microblog in Libraries
}

\author{
Lanjun Xing ${ }^{\mathrm{a}}$ \\ Shenyang Aerospace University Library, Shenyang 110136, China \\ aemail: lanjun666@163.com
}

Keywords: Microblog, Library, Information service

\begin{abstract}
Microblog is a new type of blog recently appeared in China with advantages such as short, common and easy. But there are so many information sources that it is really hard to tell which ones are true while the others are false. These characters of microblog have a great deal in common with the humanized development trend of libraries in the age of web 2.0. The combination of microblog and the future libraries will truly make the libraries everywhere.
\end{abstract}

\section{Micro Everywhere, Fashion all the time}

Nowadays, there are many new technologies used in the libraries that make them much more advanced than ever before [1-6]. Microblog is short for Micro-blogging which enables the users to update short texts in time and to issue them very openly. These texts could be sent in many ways, such as SMS, IM, E-mail, Web and WAP. Microblog is both blog and SNS but has some differences with them. Twitter in the America is the pioneer of microblog and there have been lots of websites with microblog in china now [7]. Nowadays, if someone has microblog or not becomes one of the most important signs of in or out. Comparing with blog which has distinct levels, standard styles and mature thoughts, microblog is just a short message with one sentence or just a mass texting which is neither a revolution in hardware nor an innovation in software. Microblog is very popular due to its grassroots character and there is no doubt that it will become the hotspot to lead innovation and fashion style in internet industry for the next two or three years. The form of microblog rather than the content on it, will bring the huge change to us - it causes our thought to be more multiple, fragmental and jumping.

\section{Micro words with macro meanings}

According to the CNNIC's reports, there have been 313.8 billion netizens in China by the end of June, 2009; therefore, internet has become an essential life style of them and microblog, without any question, would own most of them. With the advantages of concise and comprehensive, instant, folk and shareable, microblog has attracted much more attention and has been given much more energy all around world. Thus no wonder it is a dark horse in the internet.

\section{Characters of microblog}

- Reset space time

The seamless connection of microblog and mobile phone is revolutionary, and the similarity of microblog and SMS is timeliness; so your friends could notice and respond your updated news immediately. The phrase "super fresh" which is cited by an American IT professor could describe the Twitter about its character of real-time quite vividly. Comparing with the static room of the former blog, microblog could provide a dynamic and interactive room filled with elasticity and it is more like concentric circles which could radiate and overlap constantly. All the characters of microblog above make far become close.

- Showing bright side of humanity

Microblog has provided us a completely equal and wide open platform which makes the spread market style rather than cathedral style, so that every single person owns his own microphone to 
spread information instead of just accepting them. It not only is relaxed, convenient and easy to accept but also conforms to habits and psychological characters of modern people filled with true enthusiasm. The release and spread of information has reached the level of point-to-point and even multipoint-to-multipoint. There is no way to control the information technically.

- Extend the search mode

“Ask Google about foreign affairs while ask Baidu about internal ones” has become an inertial thinking of netizens. Thus who could we turn to when it is about what just happened? The answer is microblog. It is possible that the witnesses have already discussed something on microblog while it is not noticed on Google or Baidu yet. Microblog could do the search in real time so completely that in near future there will be a revolution in search field to change the search from static state to dynamic state.

- Refresh the consulting service

"What are you doing now?" and "See what is happening now?" are slogans of microblog that would really excite people. By grabbing the web page, it could tell you what the other people are doing and with the limit of words that no more than 200 words, people always show their present state without any protection. Therefore there comes a database filled with all kinds of states of all the people as well as a real-time consulting service with uncertain respondents and uncertain answers which need to be further judged and screened.

\section{Disadvantages of microblog}

Microblog is a compound evolution of SMS, blog and E-mail which could show everything all over the world. It brings convenience as well as some problems, and it is a double-edged sword without being appropriate deal with.

- Various subjects

Microblog is purely spontaneous private behavior with expressions of individual thoughts and selections from individual perspective. There is neither requirement of theme nor limit of writing type about microblog so that it shows an original ecology. Contents with the same theme are always put in different aeras where the themes may be continuous or not and there is no rules at all. The amount of transitions of themes could accelerate the decay rate of the theme and then bring difficulties to information integration.

- Fragmentation of content

The features that short and casual bring too much spam (Stupid Pointless Annoying Messages) to microblog and everyone could send and share any information anytime by any means due to the low requirement of the texts. Therefore, the "fast food" is disintegrated into "snacks" and the remaining point is deconstructed even further more. Our life has entered the era of fragmentation by being pushed by the mobile internet.

- Diversity of bloggers

Microblog allows everyone to have a voice and an audience and thus there are more and more users joining in the team of bloggers which has expanded the range of participants. There are not only celebrities such as Obama and Welch in Twitter but also ordinary people such as cashiers and oilers. The deconcentration of speaking right could bring more and more grassroots journalisms as well as the uncertainty of the copyright.

- Multi-dimensional information

There appears doubt about reliability of people and voices in the virtual world since the birth of internet and it is so called that network is a hotbed of rumors. There is inevitably difficile true in microblog because no one would check the contents or the themes at all.

\section{Application in the library}

The participatory and interaction of web 2.0 created this new kind of platform as microblog and made library face the choices of how to be more humanized. To achieve reader-centered, we need to 
change not only our concepts but also system and webpage as well as to improve the universality, interactivity and flexibility of the system to make the readers take part in the library's affairs and the creation of net content instead of just being spectators. More importantly than all of that, the library could be a paradise to provide services to the users anytime and anywhere.

- Information communication platform for readers

Creating microblog platform with characters of facing society, facing readers and reflecting features would make libraries show themselves and serve readers even better in web environments. This platform is equal, open, personalized and interactive for readers to participate without any boundaries. With the help of microblog, libraries could be aware of the readers' opinions, suggestions and evaluations at the first time which would make the work of information service more specifically, and the readers could notice the libraries' announcements, new book announcements and overdue information immediately. Owing to the instant and shareable characters of microblog, the information could spread all over some groups and teams with same the interests rapidly.

Readers could know the librarians' thoughts and then to communicate with them through this platform. Thus, there really comes a dynamic loop with two-way communication between library and readers which is another platform for communicating information service besides the library website, and it is the most convenient communication way even better than BBS and blogs.

- Internal academic field for librarians

The internal academic communication could be within the library or between the libraries, and it could between librarians or between librarian and professor or even between librarian and leader. Microblog makes this communication more convenient, more instant, sweeter and friendlier.

Through communication, library could get the very new information and research results sharing by other libraries and the librarians could not only take strategic thinking but also get guidance by specialists and scholars from different territories and different majors. What is more, this communication will raise the ordinary librarians' consciousness of taking part in management, increase the mutual trust between leaders and librarians and enhance the cohesion of libraries.

- Tools for pushing the resources of libraries

As in today with information overload, what a person really need of is the analyzed, handled and timely information, while the raw information on microblog apparently cannot meet this need. Now the libraries face a new subject that is to arrange, select and recombine the mass information to build up a more professional and deeper information base which is dynamic, real-time, stable and convenient for readers to browse and use.

These information aggregation and push features are carried out mainly through RSS (Really Simple Syndication) and Track-back technologies. Aggregation tools could gather the latest news from multiple information sources or websites and provide them to readers in one interface. The libraries could build up a practical and convenient internet index system through reorganizing and filtering the information and then to create a good order as well as maintain it in this chaotic internet environment.

\section{Conclusions}

Today many Chinese libraries have placed too much emphasis on database construction, but ignored the guidance that makes users get resources from outside which lead to a ubiquitous waste in constructing library digital resources. Through microblog, the libraries could introduce to readers their databases and cooperate with other libraries to achieve resources sharing. Meanwhile, the libraries might have a far better understanding of readers' individual needs to provide services for acquisition and resource allocation work which could introduce some new management technologies into libraries to make them reader-centered or even better.

\section{References}

[1] D. Li: Applied Mechanics and Materials, Vol. 321-324 (2013), p. 2721-2124 
[2] D. Li: Applied Mechanics and Materials Vol. 462-463 (2014), p. 716-719

[3] D. Li: Applied Mechanics and Materials Vol. 513-517 (2014), p. 453-456

[4] D. Li: The Application and Research on RSS Technology in Library Individual Information Service, 2013 2nd International Symposium on Instrumentation and Measurement, Sensor Network and Automation, IMSNA 2013, p 1004-1006, 2013

[5] D. Li: Study on the Web 2.0-based Internet applications in the University Libraries, 2013 2nd International Symposium on Instrumentation and Measurement, Sensor Network and Automation, IMSNA 2013, p 1007-1009, 2013

[6] D. Li: Applied Mechanics and Materials Vol.556-562 (2014), p.5813-5816

[7] Information on http://www.wikipedia.org/ 